\title{
Developing Interdisciplinary Research Partners: The Learning by Innovative Neuro Collaborations Research URE
}

\section{Dr. Barbara Burks Fasse PhD, Georgia Institute of Technology}

Barbara Burks Fasse is the Director of Learning Sciences Innovation and Research in the Coulter Department of Biomedical Engineering (BME) at Georgia Tech. Dr. Fasse studies the efficacy and value of student-centered learning initiatives and reform pedagogy, specifically Problem-Based and Project-Based Learning, in classrooms, instructional labs, capstone design, and undergraduate research experiences. She joined the BME faculty in 2007 following ten years in Georgia Tech's College of Computing where she was a member of the NSF-funded Learning By Design ${ }^{\mathrm{TM}}$ Problem-Based Learning curriculum development and research project. She also conducted an NSF-funded ethnographic study of learning in a problem-driven, project-based bio-robotics research lab at Georgia Tech. In addition to her duties in BME, she is an advisor to the interdisciplinaryScience Learning: Integrating Design, Engineering, and Robotics (SLIDER) project.

Mr. James William Schwoebel, Georgia Institute of Technology

Mr. Ethan James Craig, Georgia Institute of Technology

Mr. Anish Joseph, Georgia Institute of Technology

Ajit Vakharia, Georgia Institute of Technology

Prof. Steve M. Potter PhD, Georgia Institute of Technology

Kim Dooley, Texas A\&M University

James Linder, Texas A\&M University 


\title{
Developing Interdisciplinary Research Partners: The Learning by Innovative Neuro Collaborations Research URE
}

\begin{abstract}
This presentation reports on an undergraduate research experience (URE) designed to bridge interdisciplinary neuro-related research labs. While there are many labs on university campuses that are exploring research focused on the nervous system, they tend to work in isolation, unaware of their colleagues across campus who are also engaged with related research in a variety of different domains - a few examples include the obvious neuroengineering and neuroscience as well as cognition, artificial intelligence and human-computer interaction, environmental science, and psychology. This isolation prevents these labs from leveraging the potential for sharing resources such as knowledge, funding, professional connections, tools and equipment, as well as intellectual engagement with like-minded colleagues. Thus, one of the primary purposes of the Learning by Innovative Neuro Collaborations Research (LINCR) summer URE was to develop a connection between members of these labs and their research through a shared asset: the undergraduate researcher. This is the first step toward the ultimate goal of building a broad-based, interdisciplinary neuro-technology community. It is a model that can be applied to other initiatives seeking to encourage and support interdisciplinary collaboration.
\end{abstract}

Established in the Wallace H. Coulter Department of Biomedical Engineering at the Georgia Institute of Technology (Georgia Tech), LINCR is similar to the China Undergraduate Research Program (CURE) which was an NSF-funded URE designed to test the efficacy of linking the research of global-partners through undergraduate students assigned to related projects in both labs. ${ }^{1}$ Similarly, the goal of LINCR, funded by a GT FIRE (Georgia Tech Fund for Innovation in Research and Education) Grant, is to establish a collaborative relationship between research labs that do not have a link in physical space yet have interests and work that are similar enough in nature to be reason for collaboration - or, certainly, conversation. The benefit to the undergraduate LINCR Fellows, beyond participation in laboratory research itself, is the opportunity to experience the two labs and their idiosyncratic ways of working, communicating, using their physical environments and resources while exploring the ways in which they are similarly connected through the projects, literature, theory, and practice.

The first LINCR Fellow cohort-Summer 2012 — enrolled three undergraduate students from two departments linking six labs, Principle Investigators, and mentors. Each LINCR Fellow designed a research project that would benefit both of the research labs that they recruited as partners. We used traditional qualitative methods to study the outcomes of the programinterviews, surveys, journals, and student-developed artifacts. This presentation will present the lessons learned that answer the question: In what ways can an undergraduate researcher foster collaboration between independent labs doing similar work? 


\section{Introduction}

Interdisciplinary collaboration is common throughout industry, academia, the federal government, and nonprofit organizations. ${ }^{2}$ The current market for research and development in the US is $\$ 400.5$ billion each year, growing at an annual rate of $5.8 \%$, with roughly $30 \%$ of these alliances (\$120.15 billion) involving interdisciplinary research collaboration. ${ }^{2}$ Thus, it is predictable that interdisciplinary research will continue to be important for the progressive understanding of increasingly complex problems. It can also be predicted that younger scientists and engineers will have more exposure to interdisciplinary sciences and perhaps less commitment to one specific field. ${ }^{2}$ Therefore, it is important to consider methods that have the potential to successfully jumpstart interdisciplinary collaborations in the academic context - to both develop educational materials to prepare students for real-world situations and to promote more integrated and translationally-useful forms of research.

Strategies and factors for successfully starting and sustaining interdisciplinary research collaborations have been identified in the literature. Overall, a mix of both educational and research aspects were prominent in the most successful research programs. ${ }^{3-6}$ Programs that focused on having an open-minded culture with interdisciplinary research facilities seemed to spark sustaining and meaningful collaborations. ${ }^{7,8}$ Programs that sustained a feeling of social cohesion among undergraduate researchers (e.g. group meetings, community outreach activities, etc.) seemed to provide a foundation for the program to have lasting impact on student careers. ${ }^{5}$, 9,10 New research centers or interdisciplinary initiatives tend to iteratively encourage new interdisciplinary research collaborations which are often tied to education. ${ }^{8}$ Also, student-led and student-centered research and education initiatives seem to prepare students well for their careers. ${ }^{11}$ Together, these factors seem to help enhance the utility and strength of emerging interdisciplinary research collaborations but remain fairly specialized and fragmented.

If these factors were combined, interdisciplinary research collaborations resulting from student projects could become stronger. Specifically, it can be hypothesized that the features listed below could contribute to a successful and personalized interdisciplinary research program:

1) a community culture or research center that promotes collaboration and unity among research labs dedicated to a particular cause (e.g. Stone et al, ${ }^{8}$ );

2) a research culture that connects well with other local, national, or international research communities (e.g. Perez-Castillejos $2012^{5}$ - test device in local community);

3) a research culture tied closely to interdisciplinary educational structures available to undergraduate students (e.g. Clase $2008^{12}$ - bioscience/physiology classes merged with bioengineering classes);

4) an academic and research community that has close external ties to mentors in the local, national, or international community (e.g. student, nonprofit, clinical, professional, and industry networks); 
5) an academic and research community that facilitates interdisciplinary undergraduate research and undergraduate publication in peer-reviewed research journals; and

6) a social unity and alignment among student and faculty researchers (e.g. volunteer outreach activities, community projects)

Few studies, if any, have looked at the effectiveness of undergraduate-based research programs to initiate interdisciplinary research collaborations between two labs that have not been previously collaborating. In this paper, we will report on the lessons learned in the first implementation of a novel, undergraduate-created and -managed summer research program (LINCR) that addresses these problems as applied to the domains of neuroscience, neuroengineering, psychology, computer science, and other disciplines related to neuroscience. This paper will discuss the LINCR model in greater depth and analyze the results of the pilot program implemented during Summer 2012.

\section{Research Design}

We employed qualitative case study design to answer first-round research question: what could we learn from the first cohort about LINCR's potential for linking research and research labs through undergraduate researchers as a shared asset? ${ }^{13-15}$ The participants' cases-- their individual and collective experiences - form the basis and unit of study. ${ }^{16}$ Since case study design does not lay claim to methodology unique to itself, we are drawing from standard qualitative methods such as participant observation, interview, and self-report accounts. We have developed the thick description necessary for authentic understanding of a social phenomenon by triangulating a variety of sources in order to assure reliability, dependability, and authenticity. ${ }^{15}$, 17-21 Data sources were compared within each subject, between subjects, and across sources to develop a thorough understanding of LINCR as enacted in the first iteration, Summer 2012.

Constant comparative methodology was used to concurrently collect and analyze data while the subjects were engaged in the activity, which then generated more questions and opportunities for clarification submitted at that time and after they finished the fellowship. ${ }^{22}$ As is consistent with a qualitative research approach, a control group was not used to compare the data, instead the comparisons are within and across the unit of study: the cases.

\section{Methods}

The LINCR URE is of interest for its direct impact on the individual student participants as well as its broader implications on neuroscience education and research collaborations. The goal of the first round of assessment reported here is to define and describe the lessons learned for improving subsequent implementations. This report represents the first LINCR cohort's experience during the Summer 2012 term.

Participants 
The very nature of an interdisciplinary project calls for the enrollment of participants from multiple disciplines and/or departments. In this case, it also called for engagement across a variety of roles: that is, the research lab environments ( $\mathrm{n}=6$ in three pairs), Primary Investigators $(n=6)$, graduate student mentors $(n=6)$, and the undergraduate LINCR Fellows $(n=3)$. The complex interactions between these elements prevents this analysis from being devoid of influence from each - meaning that we cannot study the LINCR URE or the LINCR Fellows' experience without also examining the influence from and on the other elements/roles.

All participants were made explicitly aware that they were the subjects in a funded research project studying the effects of their participation in LINCR. They signed IRB-approved consent forms to acknowledge their agreement to participate as well as to approve the use of their artifacts as data.

Undergraduates:

Georgia Tech undergraduate students were recruited by announcement and email. Three students were chosen and were funded to participate as LINCR Fellows - two from the Coulter Department of Biomedical Engineering at Georgia Tech and one from the School of Chemistry and Biochemistry also at Georgia Tech (Table 1).

Lab Personnel:

The Principal Investigators (PIs) were identified and recruited by each individual LINCR Fellow. Graduate student mentors were then recruited by the PIs. All of the labs were on the Georgia Tech campus. They were paired across three departments: BME, Chemistry, and Electrical Engineering. Table 1 profiles the distribution of the LINCR Fellows across the departments and the projects that they developed. 


\begin{tabular}{|c|c|c|c|}
\hline \multicolumn{4}{|c|}{ Applicants Selected for LINCR Fellows Program - Summer 2012} \\
\hline $\begin{array}{l}\text { LINCR } \\
\text { Fellow }\end{array}$ & $\begin{array}{c}\text { Lab } 1 \\
\text { Building/Department }\end{array}$ & $\begin{array}{c}\text { Lab 2 } \\
\text { Building/Department }\end{array}$ & Project Title \\
\hline $\begin{array}{l}2^{\text {nd }} \text { year } \\
\text { Biochemistry } \\
\text { student }\end{array}$ & $\begin{array}{l}\text { Whitaker BME } \\
\text { Building (Biomedical } \\
\text { Engineering) }\end{array}$ & $\begin{array}{l}\text { Ford Environmental } \\
\text { Engineering Building } \\
\text { (Chemistry) }\end{array}$ & $\begin{array}{l}\text { "Using Mass Spectrometry } \\
\text { (MS) Techniques to } \\
\text { Understand Neural Repair } \\
\text { Mechanisms in Traumatic } \\
\text { Brain Injury (TBI)" }\end{array}$ \\
\hline $\begin{array}{l}2^{\text {nd }} \text { year } \\
\text { BME student }\end{array}$ & $\begin{array}{l}\text { Whitaker BME } \\
\text { Building (Biomedical } \\
\text { Engineering) }\end{array}$ & $\begin{array}{l}\text { Molecular Science } \\
\text { and Engineering } \\
\text { Building (Chemistry) }\end{array}$ & $\begin{array}{l}\text { "Connecting Multi-Electrode } \\
\text { Arrays (MEAs) with } \\
\text { Nanoparticles for Controlled } \\
\text { Drug Delivery" }\end{array}$ \\
\hline $\begin{array}{l}2^{\text {nd }} \text { year ECE } \\
\text { student }\end{array}$ & $\begin{array}{l}\text { Whitaker BME } \\
\text { Building (Biomedical } \\
\text { Engineering) }\end{array}$ & $\begin{array}{l}\text { Tech Square Research } \\
\text { Building (Electrical } \\
\text { Engineering) }\end{array}$ & $\begin{array}{l}\text { "The Application of Electro- } \\
\text { stimulation Techniques and } \\
\text { Nonlinear Models to } \\
\text { Understand Cortical Function } \\
\text { of Awake Animals." }\end{array}$ \\
\hline
\end{tabular}

Table 1: This table highlights the accepted LINCR proposals. It lists the LINCR Fellow's year of matriculation, lab partners, and project title.

Data Sources

The data sources for this report consist of carefully programmed surveys triangulated with observations and field-notes from site visits to the labs as well as informal and formal interviews with the participants.

\section{LINCR Surveys:}

The Fellows, PIs, and mentors were given scheduled self-report surveys that allowed us to monitor engagement in real-time while also providing the summative data needed for profiling engagement as an artifact of this research project. The LINCR survey format was derived from the structured journal developed for and used by the CURE project. ${ }^{1}$ The object of using a structured journal format is to prompt participants to reflect on their experience in real-time because accuracy of memories tend to be heavily influenced by the final experiences thus introducing three of Schacter (23 seven memory flaws: transience (decreasing accessibility of information over time), absent-mindedness (inattentive or shallow processing that contributes to weak memories), and blocking (temporary inaccessibility of information that is stored in memory). To control for this, the structured journal was designed to serve as a series of in-theminute, real-time surveys in which students were given a prompt as a topic for focusing each week's reflection as well as to report their engagement as it developed over time. Its utility as a tool is to increase the validity of the data by avoiding post hoc interviews or surveys that would be limited by recollections and re-creations. The prompts also provided a therapeutic tool for the students as a neutral place to vent their frustrations, share their triumphs, and distill their experiences. Using the CURE journal as a model, we crafted the LINCR survey with prompts 
designed to elicit the participants' account, in all three roles, of their impressions and descriptions of their experiences as they were engaging with the program (Appendix A).

The LINCR surveys, available to the participants online using the GTNeuro.net website (powered by Drupal 6.0's webform feature, secured with AES encryption), were utilized to monitor and understand the perspectives of LINCR Fellows (biweekly), PIs (monthly), and mentors (biweekly) before, during and after the LINCR program. The survey instruments were developed by the LINCR planning committee and were sent out to the relevant user groups as reminders via the Boomerang application attached to Google mail. These short feedback forms were used to assess how the collaborations were proceeding and/or ask the graduate students how valuable the collaborations are to their particular research. We took survey data in a biweekly capacity to see how impressions change throughout the program with the joint lab meetings, as well as to continually refine the program to meet the needs of all involved in the program.

The survey data was kept private and confidential in order to encourage authentic, honest communication unfiltered by self-protective fear of disclosure. The survey use as a research instrument was explicitly communicated to and understood by all participants. As promised, identities and identifying factors have been disguised in this report.

\section{Interviews:}

Periodically, the LINCR coordinator also scheduled meetings to interview the PIs, mentors, and the LINCR Fellows to check on their progress throughout the program. Another goal of these interviews, triangulated with the surveys, was to hold each user group accountable to the expectations established at the beginning of the program by the LINCR planning committee.

LINCR Fellows had the opportunity to engage socially with each other throughout the program with events planned by the LINCR coordinator. These social opportunities included activities such as volunteering, lunch/social events, and industry events. The goal of these activities is to establish a close-knit LINCR community.

Procedure

The overarching goal of the LINCR Fellows program is to promote successful interdisciplinary research collaborations through a full-time (40 hours/week) undergraduate research program lasting 13 weeks. Specifically, this program allows for an undergraduate student to identify two possible collaborators and then to propose, select, and carry out a new collaborative neuroscience research project that brings together two research groups in separate buildings on Georgia Tech's main campus. It was required that the projects link groups that were not previously collaborating. The program provided seed funding to jumpstart original collaborations within Georgia Tech's neuroscience and neuroengineering community ( $>60$ labs). 
Unique features of the LINCR program include:

1. It is undergraduate-led and undergraduate-maintained, with 1 main undergraduate LINCR coordinator paid a stipend to coordinate lab meetings;

2. The LINCR collaborations happen in parallel as opposed to serially (Fasse \& Benkeser, 2011);

3. Educational prompts/biweekly research updates are a unique asset to the program, and are tied to a Drupal 6.0 website template with a keyword-searchable database;

4. Email reminders to complete the biweekly/monthly research prompts (PIs/mentors/LFs) and educational prompts (LFs) were sent out using a Boomerang application synchronized with google mail (gmail). This allowed for pre-programmed email messaging that can be set-up at the beginning of the program;

5. The LINCR coordinators (composed of 4 undergraduates) used Google Hangout as a means to communicate and maintain the program over the summer allowing three of them to participate remotely;

6. Planning for the culminating symposium that closed the LINCR URE was done using officer positions within an undergraduate student organization (GTNeuro);

7. The program is sustained through an undergraduate student organization with professional—faculty and private sector-- mentors (e.g. acquiring funding, writing grants to grant agencies).

\section{Partner recruitment:}

Potential lab partners were identified using various websites available from the Georgia Tech homepage. Over 60 neuro-related research labs were found on Georgia Tech's campus. These labs, along with descriptions from the websites, were then imported onto the GTNeuro website to enable keyword search and integration into other events and laboratories related to GTNeuro.

After securing funding for the LINCR program via a GT FIRE grant, a brochure was created to increase awareness of neuro-related labs, PIs, and projects. This brochure separated each laboratory by location as depicted on a Google map (Figure 1). It was used to pinpoint locations of labs with like-minded potential collaborators. We hypothesized that identifying the geographical locations would aid student selection of research labs by highlighting gaps in collaboration around Georgia Tech's campus. The LINCR brochure was freely available online at the GTNeuro website as well as in a color print paper edition. The printed LINCR brochure was distributed to all the faculty members that were included in the brochure and to anyone inclined to promote the program. 


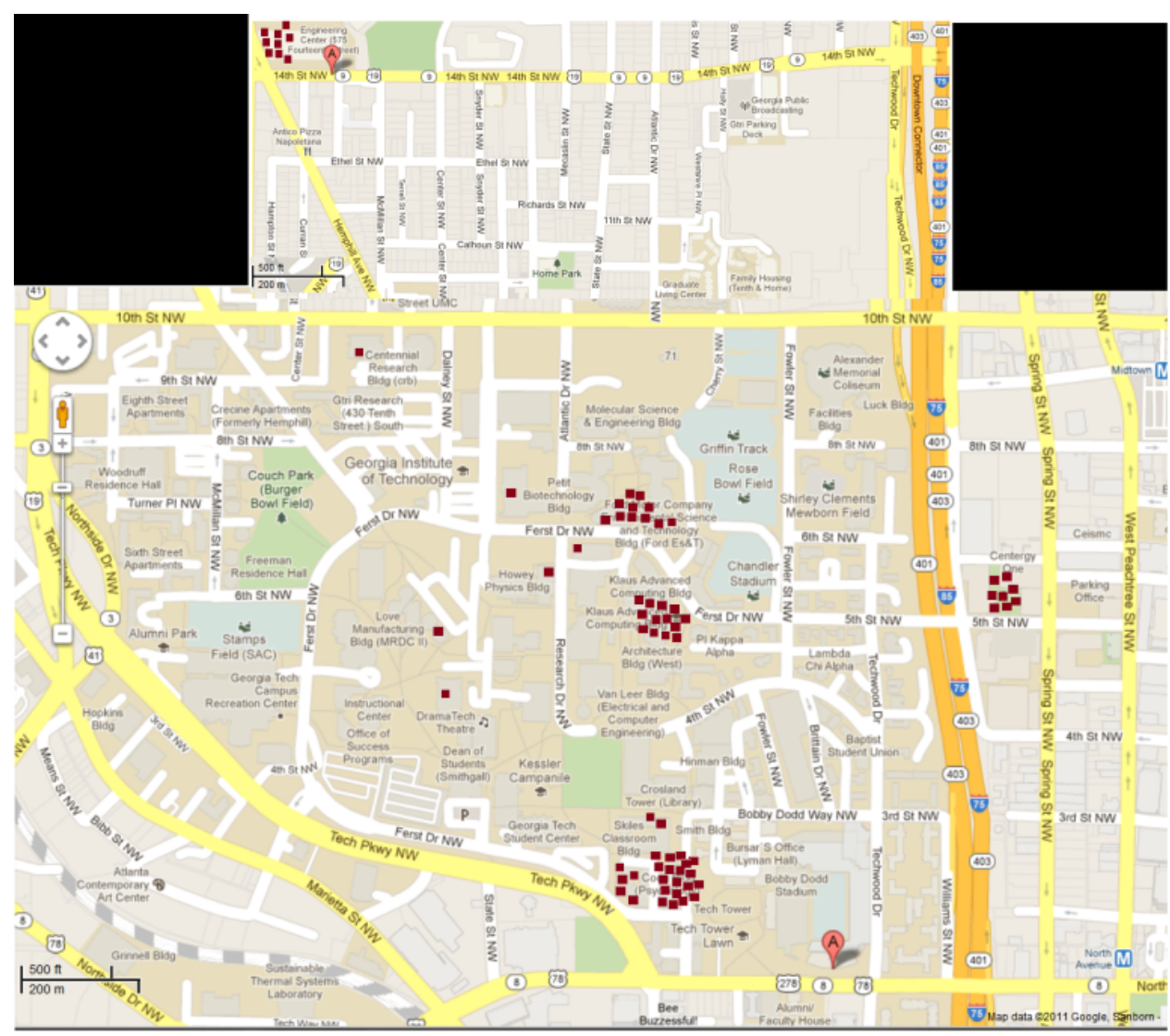

Figure 1: Each red dot represents a neuro-related lab on Georgia Tech's campus. This figure shows that a significant amount of neuro-related research occurs at Georgia Tech, much of it in clusters, yet the neuro culture is primarily polarized and fragmented.

\section{General LINCR Program Structure - Biweekly Lab Meetings:}

It was originally intended that each LINCR Fellow (LF) would arrange a biweekly meeting where both PIs and mentors could be in the same room to discuss the LINCR project. However, this turned out to be an impractical demand due to lab scheduling difficulties. Therefore, each LINCR Fellow negotiated his/her own structure for collaborating between their two labs depending upon each lab they were associated with and availability of the PI.

Mentors from both collaborating labs were expected to mentor the LFs as necessary for the scope of the project. Initially, we predicted this might include training of simple techniques with the LFs gradually taking initiative to proceed into independent research. Our goal was for the roles to eventually reverse. The LFs, as the link between the two collaborating labs, would teach graduate students, on both sides, ways to combine technologies and lab techniques that are beneficial for both labs.

Mentors were also asked to provide LFs with relevant literature sources to their project. Ideally, LFs would receive this literature at the beginning of the program and master the 
literature by the end of the program. Mentors were also required to attend the final LINCR symposium. This symposium was intended to promote community building as well as to build collaborations not only within the proposed LINCR collaborations, but to extend into the other labs attending this conference.

A unique aspect of the LINCR program was that the LFs were also required to complete biweekly educational prompts throughout the program as pilot materials for an educational class in the proposed neurobiotechnology curriculum at Georgia Tech (Appendix B). A sample solution created by the LINCR planning committee was provided for each educational prompt to guide the LFs through the educational prompt process. These prompts were intended to inform LINCR fellows about possible ways to translate their LINCR research experience beyond just 'pure research' into possible projects in the Atlanta community and also inform research mentors and principal investigators about possible opportunities to expand the scope of the project beyond Georgia Tech in the future. These prompts provided guidance for the LINCR Fellows' background research throughout the program and aligned their research projects with existing entities to support the research project in Atlanta. Specifically, these meetings were designed to help the LINCR Fellows extract information about classes at Georgia Tech (e.g. ECE 2025 Digital Signal Processing), industry organizations/companies (e.g. Medtronic), professional (e.g. IEEE) and volunteer nonprofit organizations (e.g. MS Society), other research correlates at other local universities (e.g., Georgia State University and Emory), clinical connections (e.g., Grady Hospital - Marcus Stroke Center), grant opportunities (e.g., President's Undergraduate Research Award), professional publications/conferences (e.g., BMES Conference), and existing student organizations (e.g., Active Minds - a mental health awareness student organization) related to their LINCR projects. At the end of the program, the LINCR Fellows should have acquired the background knowledge and resources necessary to follow through and expand the project into the future (if appropriate).

\section{Results}

In this paper we present the first-round analysis of the LINCR model in greater depth and analyze the results of the pilot program implemented during Summer 2012. We were most curious to how the LFs, mentors, and PIs would utilize the resources that each offered the other.

The application and initiation processes were rigorous, with each applicant required to approach and bridge the two labs, establish a commitment from two PIs, and design a project that would be appealing to partners in both labs. This may indicate that this program is best suited for self-directed, experienced undergraduate researchers:

- LF 1 - "I was already a member of the A Lab and then contacted Dr. B by email. I then met with Dr. B and we discussed potential projects."

- LF 2 - "I emailed professors sharing my interest, making sure that I made it clear that I would be awarded funding. I sat down with multiple professors, learned about what they 
did in their labs, shared ideas of my own for collaboration, and brainstormed on new ideas with them."

- LF 3 - "I was a member of C's lab. I went to Dr. C's office to tell Dr. C about my original proposal, and he contacted Dr. D my behalf."

LINCR Fellows - Lessons Learned about Linked Research

As is typical of qualitative case study research, the data is sensitive to project-specific details and the culture of the individual labs. This section is divided into LINCR Fellow (LF) cases (LF 1/2/3 results), General LF Results, Mentor Results, and PI Results. This paper uses individual cases to support our claims.

Sharing Material Assets Between Facilities: LINCR Fellow 1

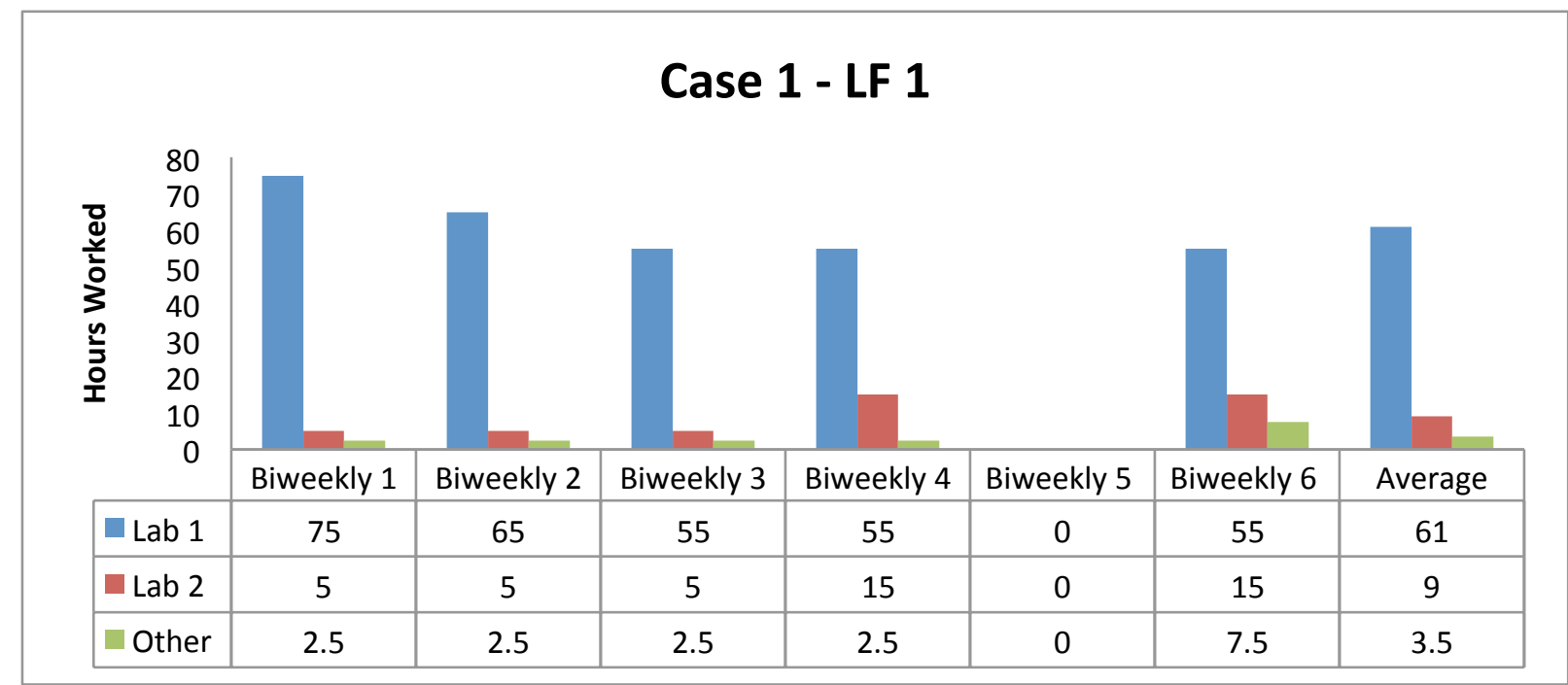

Figure 2: This chart represents LINCR Fellow (LF) 1's lab 1, lab 2, and other participation during different biweekly intervals in the LINCR program. In this way, one can see how the activity of LF 1 changes with time.

In this first case, it can be seen that LINCR Fellow 1 (LF1) spent much more time in Lab 1 than Lab 2 (Figure 2). LF1 spent more time in Lab 1 because this lab focused on the tasks of active staining, cryrosectioning, slide preparation, and image analysis. LF1 reported: "Preparing sections for imaging," taking 55 hours during week 3 . This inherently took more time than the activities in Lab 2, which included setting up a mass spectrometer machine and analyzing samples. In week 3, LF 1 reported: "Getting the MS to work; calibrating and preparing it for samples," only taking 5 hours. Thus, LF1 mainly utilized the technologies in Lab 2 to further analyze the biological samples in Lab 1 . This illustrates how interdisciplinary research partners, such as the LINCR program, have the potential to expand their research by sharing materials between facilities, expertise, and resources (e.g. \$3 million mass spec machine with mentorship) to establish high-value research. 


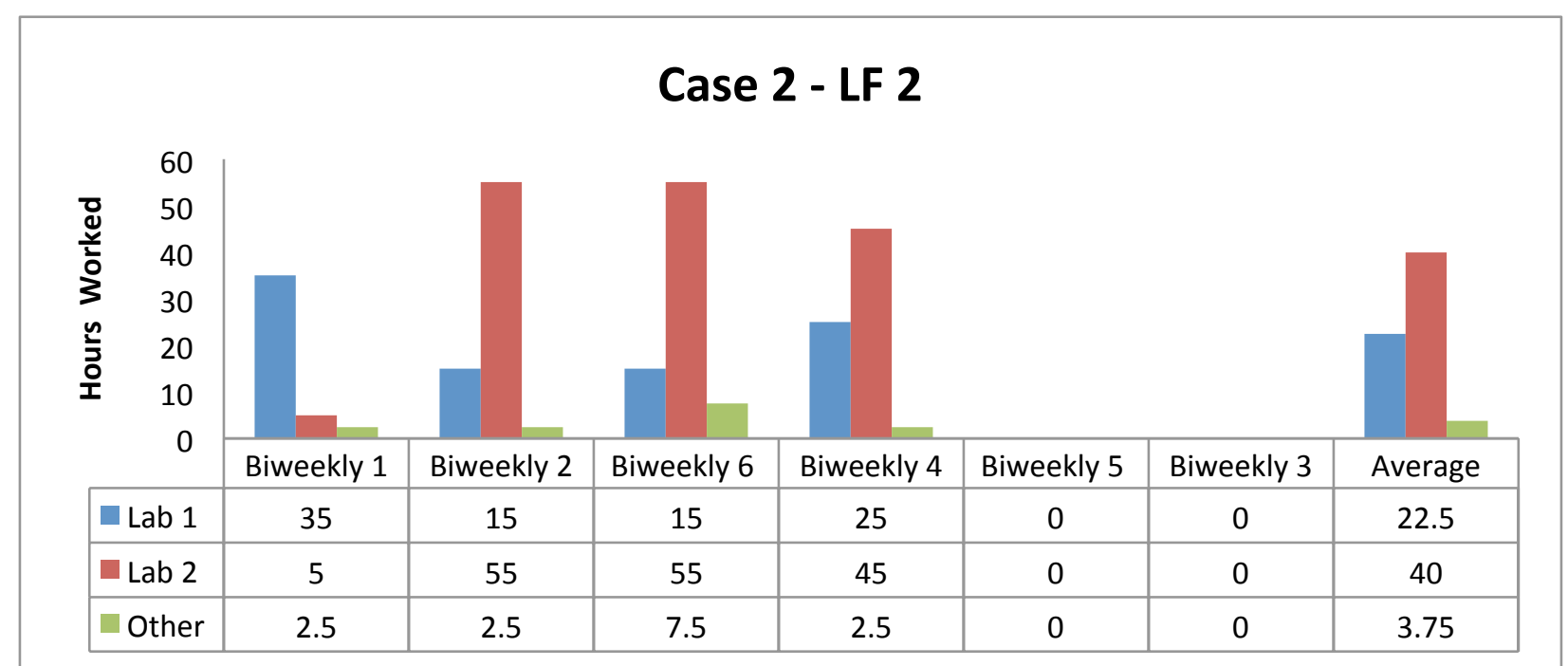

Figure 3: This chart represents LINCR Fellow (LF) 2's lab 1, lab 2, and other participation during different biweekly intervals in the LINCR program. In this way, one can see how the activity of LF 2 changes with time.

LINCR Fellow 2 (LF2) seemed to initially spend most time in Lab 1 (35:5), and then during the second biweekly update, the Fellow abruptly shifts into Lab 2 (15:55). By the end of the program, LF2 has more balance in the time commitments between the two labs (Figure 3). Looking through the qualitative feedback sheds light for why this is the case. In the beginning of the program, the PI and mentors in Lab 2 were out of town, so this describes why LF2 spent most of the time in Lab 1 for the first 2 weeks. During biweekly update 2, the lab mentors for Lab 2 returned and the workload shifted in favor of Lab 2. LF2 reported: "Learning flow cytometry on CHO cells and neurons, imaging neurons; analyzing binding of NPs to neurons by these two methods," taking 55 hours as reported in update 2 . This trend continued throughout the rest of the program, with Lab 1 focusing on preparation for flow cytometry, and Lab 2 on implementing flow cytometry for the nanoparticle binding project. Also, the project continued to favor Lab 2 participation because the technology to be used in Lab 1 was delayed in its shipment. In update 4 LF said, "MEAs still haven't arrived yet". This demonstrates the way in which a shared project can be balanced to compensate for absences of one lab or mentor, self-correcting to meet and sustain the research collaboration. This allows for the work to continue to make progress as the two labs absorb the knowledge or expertise vacuum that might be created when a mentor or PI are not available. The partner lab simply provides the support during the absence. 


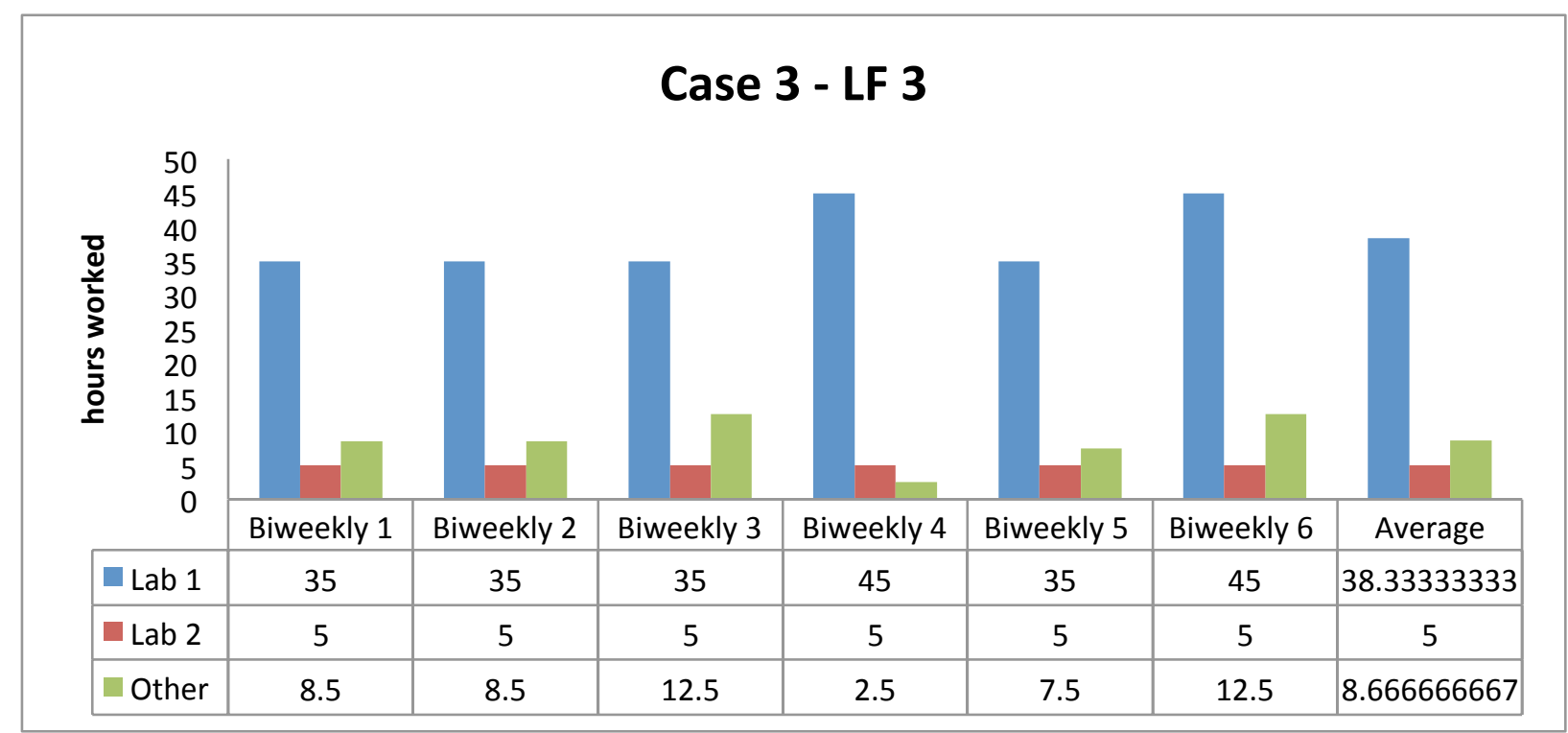

Figure 4: This chart represents LINCR Fellow (LF) 3's lab 1, lab 2, and other participation during different biweekly intervals in the LINCR program. In this way, one can see how the activity of LF 3 changes with time.

LINCR Fellow 3 (LF3) seemed to spend most time in Lab 1 (averaged 38.33 hours) all throughout the program with variable activity in Lab 2 (averaged 5 hours - see Figure 4). LF3's project centered on animal studies, so greater participation was necessary in one lab (Lab 1) over the other (Lab 2) According to LF3: "Working with animals; Shadowing and assisting with surgeries; Trying to figure out what kind of electrodes to implant" accounted for 35 hours as reported in update 2. This inherent bias was from the nature of the work in Lab 2, which focused on learning how to use LabView within the scope of the electrodes in Lab 1 (e.g. less time required). In update 2, LF3 said that "Learning how to use LabView; Developing a stimulus generator with LabView," only took up 5 hours. Overall, this case illustrates how skills learned in one lab can be applied to the other setting without requiring extra time for training (e.g. Labview algorithms, stimulus generator, animal studies/electrodes). Here the Fellow spent less time in one lab because the work being done there required less time but then he was able to utilize the skills in both labs.

Analyzing LINCR Fellow Cases

With this pilot data, one can extrapolate trends from these 3 cases. These trends include:

- LINCR Fellows tended to spend significantly more time in one lab over another (Figures $2,3,4)$

- LINCR Fellows tended to interact with one mentor more frequently than the other mentor (Figure 5) 
- There exists great variability in the cases, showing that the time spent in each lab is probably dependent on the individual structure of each lab or the nature of the project (Figures 2, 3, 4)

- Outside work constituted a small amount of time for the program relative to time in lab (Figures 2, 3, 4)

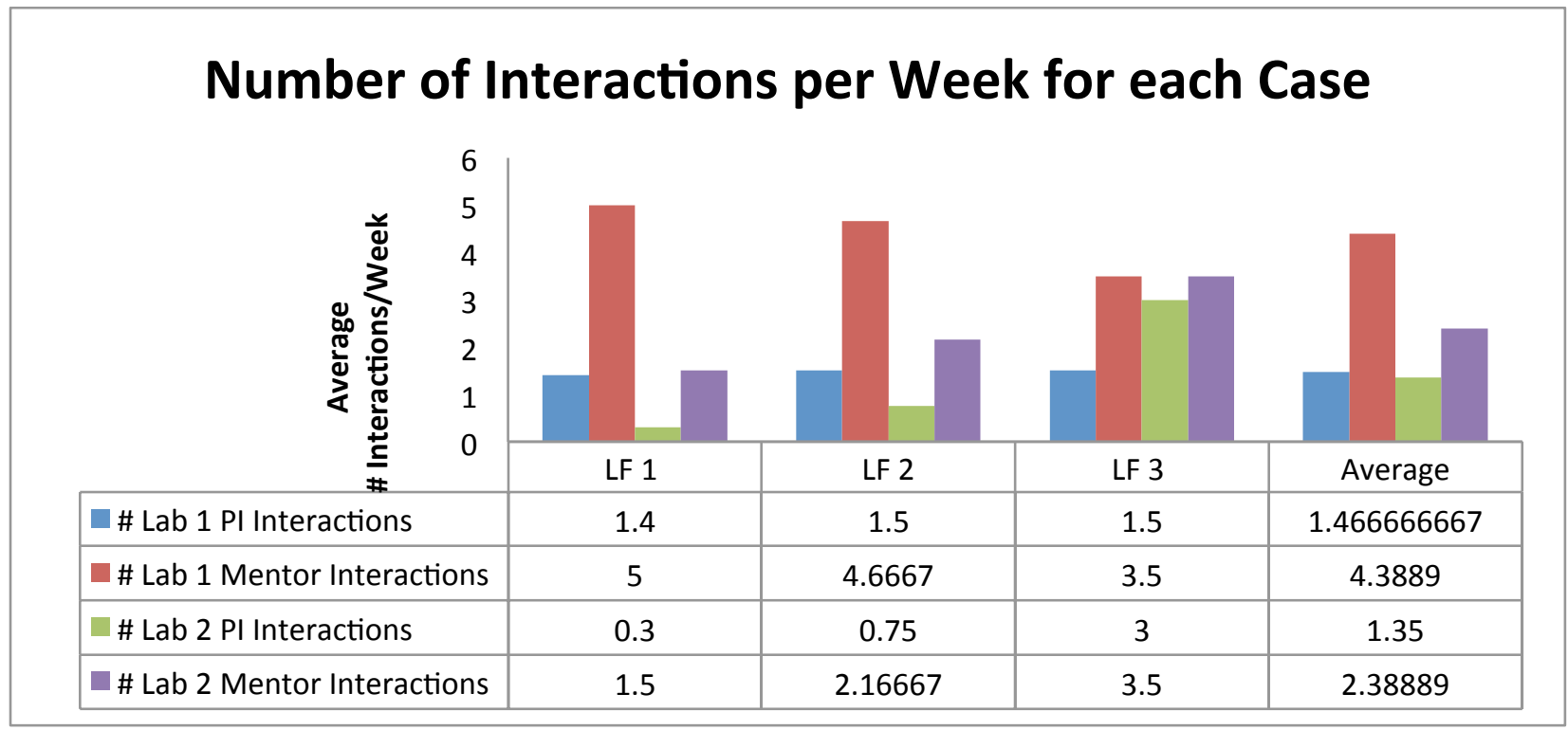

Figure 5: This chart represents all LINCR fellows and their interactions with lab 1 and lab 2 $\mathrm{PIs} /$ mentors. From these statistics is noticeable that LINCR Fellows tended to interact and communicate with one lab over the other. 


\section{Mentor Response Participation (By Total)}

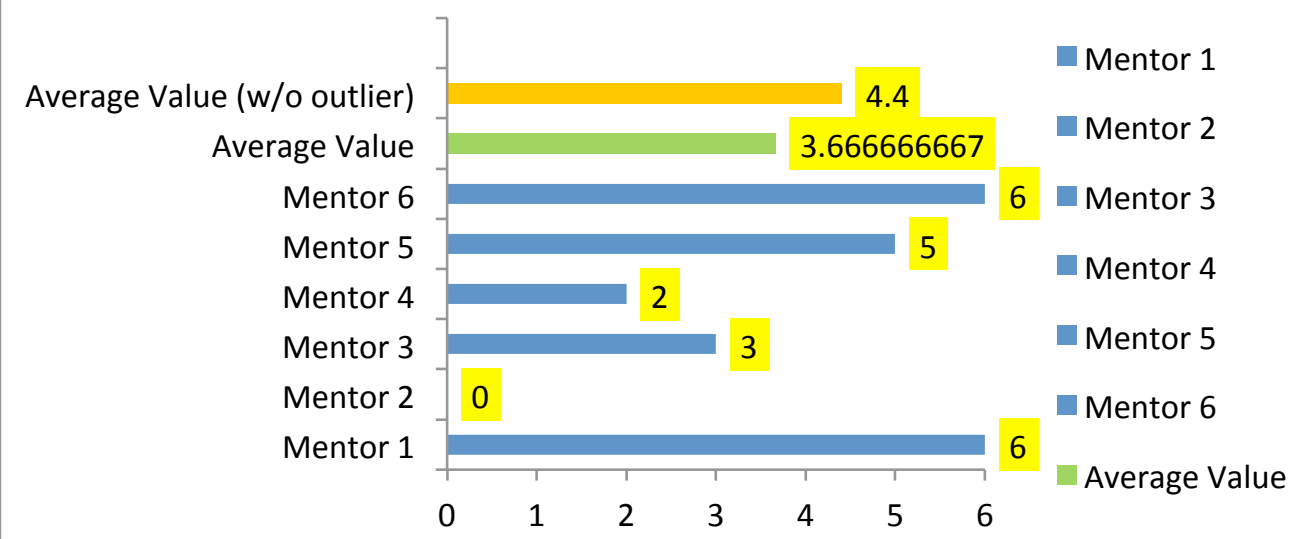

Figure 6: This chart shows the mentor participation in the biweekly research prompt process. 5 out of 6 mentors completed at least one biweekly prompts. More specifically, 2 mentors completed all prompts, 1 completed 5 prompts, 1 completed 3 prompts, 1 completed 2 prompts, and 1 did not complete any prompts. Thus, the data is inherently biased toward mentor 1 and 6 (who completed the most prompts).

\begin{tabular}{|c|c|}
\hline Prompt Question (Mentors) & Average (if possible) or Result \\
\hline $\begin{array}{c}\text { Average hours interacted with LF's project in } \\
\text { past 2 weeks }\end{array}$ & 8.34 hours/2 weeks or 4.17 hours/week \\
\hline $\begin{array}{c}\text { Number of mentor-mentor interactions every } 2 \\
\text { weeks }\end{array}$ & 1.32 meetings/2 weeks or .66 times/week \\
\hline $\begin{array}{c}\text { LF's project with regard to mentor's own } \\
\text { project and ambitions }\end{array}$ & $\begin{array}{c}\text { Distracting (18\%), somewhat worthwhile } \\
(50 \%), \text { fairly worthwhile }(18 \%), \text { essential } \\
(14 \%)\end{array}$ \\
\hline $\begin{array}{c}\text { Biweekly mentor-LF communication mediums } \\
\text { Email (80\%), phone }(20 \%), \text { in person }(77 \%), \\
\text { did not communicate }(6.7 \%)\end{array}$ \\
\hline
\end{tabular}

Table 2: This table represents the questions and answers related to the biweekly mentor research prompts

From these responses, it can be generally concluded that:

- The majority of mentors thought that the LF projects were somewhat worthwhile

- Mentors learned useful information from the LINCR projects (e.g. dish cleaning technique, lower impedance electrodes, etc.)

- Website feedback response system can be used to log problems with the program to improve program for next year

- Mentors gave useful input both in person and prompts on how to improve the program 
- Mentors were most supportive when the LF's work aligned with the mentor's Ph.D. thesis or post-doc work (e.g. learning mass spec as a way to advance Ph.D. thesis)

- Time constraints prevented LINCR planning committee from clearly articulating mentor responsibilities before the program

- In the future, we hope that mentors propose projects, so that we can create more useful, high-impact and sustained projects

LINCR PI Engagement: Lessons Learned

Overall, it was difficult to get PIs to actually complete the prompts via email (only $50 \%$ of PIs completed at least 1 prompt), suggesting that it may have been better to schedule interviews to collect qualitative data (Figure 7). Communication mechanisms between the LINCR planning committee and the PIs also seemed to break during program. Even with this scarce data, useful information can be extracted (Table 3).

\section{PI Prompt Responses (by Total)}

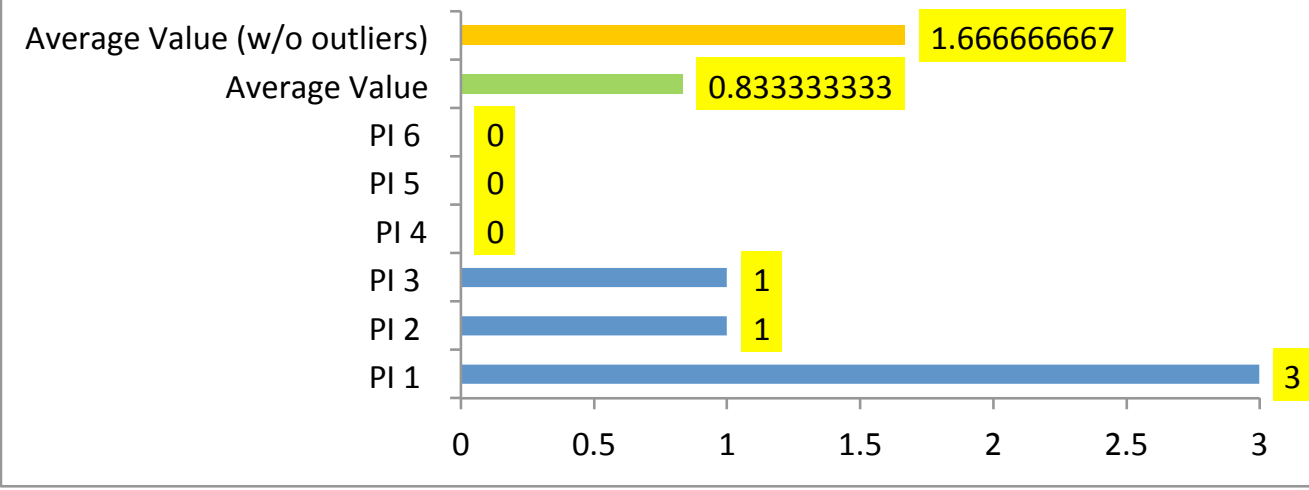

Figure 7: This figure represents the prompt completion rate of each PI involved in the LINCR program. Email reminders were sent monthly via boomerang, and only 50\% of the PIs responded to at least one prompt. Note that the data is inherently biased toward PI 1. 


\begin{tabular}{|l|c|}
\hline \multicolumn{1}{|c|}{ PI Prompt Question } & Average (if possible) or Result \\
\hline Number of PI-PI interactions per month & .60 times/month \\
\hline $\begin{array}{l}\text { The PI's interpretation of the mentor's } \\
\text { receptivity to the LINCR Fellow project }\end{array}$ & Very receptive (80\%), receptive (20\%) \\
\hline Frequency of PI-LF interactions & 1.9 times/week \\
\hline Medium of communication between PI and LF & Email/personal lab meeting (100\%) \\
\hline $\begin{array}{l}\text { PI's interpretation of the LF's interest on } \\
\text { project }\end{array}$ & Very interested (80\%), mostly interested (20\%) \\
\hline PI-PI communication mediums & Email (33\%), in person (33\%), or other (33\%) \\
\hline $\begin{array}{l}\text { PI interpretation of the collaboration with other } \\
\text { lab }\end{array}$ & $\begin{array}{c}\text { Moderate-strong (20\%), moderate-weak } \\
\text { collaboration (60\%), weak collaboration }(20 \%)\end{array}$ \\
\hline
\end{tabular}

Table 3: This table represents the questions and answers related to the monthly PI research prompts

Overall, PIs had mixed reactions to the collaborations but there seemed to be a general consensus that at least some form of collaboration was established by the end of the program, with some projects being stronger than others - thus accomplishing the goal of the program (Table 3).

Prompt analyses (post-program)

We are still in the early stages of post-program monitoring and analysis even as we plan for capturing longitudinal data in the future. Longitudinal data from mentors, LFs, and professors is not yet available. We intend to continue to collect data from our participants in twice-annual surveys to determine the lasting effects of participation on this program. Anticipated data include overall educational utility of the program as well as project sustainability (evidenced by grant applications) and impact in the Georgia Tech community.

We are already beginning to see how the first implementation of LINCR seems to be making an impact on collaborative efforts at Georgia Tech. For example, a Center for Human Achievement of Movement and Performance (CHAMP) has been proposed as an interdisciplinary research center for movement disorders. This was originally a proposed LINCR project self-assembled into a PI initiative to start a new collaborative research center designed to cultivate a community of interdisciplinary research. Additionally, the Health Technical Director at Georgia Tech Research Institute (GTRI), a well-funded independent research entity affiliated with Georgia Tech, has indicated an interest in involvement with LINCR. This individual has recommended multiple GTRI projects for the LINCR program for future years. Thus, impact from the LINCR program was by no means local - it has had and continues to have viral effects all throughout the Georgia Tech and the Atlanta community to spur on project collaboration ideas between Principal Investigators. 
Preliminary Results of Biweekly Educational Prompts

In interviews, most LFs indicated that the biweekly educational prompts helped them understand how the scope of their projects could be expanded and adapted into the Atlanta community. LFs also liked how the prompts were used to customize the program around each of their interests from these prompts (e.g. we asked them in the beginning their career goals to customize program around those career goals). Biweekly educational prompts also gave the LINCR coordinators ideas about how to expand the projects into the future and to network with other professionals in the field according to individual projects. These networks were in turn invited to the LINCR symposium via the LINCR planning committee.

\section{Discussion and Conclusion}

In this research study, a full-time (40 hours/week) summer undergraduate research program ('LINCR') was implemented. This program allowed undergraduates to propose and carry out a new collaborative neuroscience research project that brings together two research groups in separate buildings on Georgia Tech's campus, groups that were not previously collaborating. Throughout this program, real-time qualitative feedback was collected from students, mentors, and PIs through a research update system to adjust the program to optimally meet the goals of all involved and to analyze the success of the program at different time points (e.g., problem domains above). Biweekly educational prompts were also given to the LFs to expand the research project into the local Atlanta community.

This pilot study is one of the first studies to indicate success in a summer undergraduate research program implemented in parallel by an undergraduate-led organization (GTNeuro). If this situation can be generalized to other contexts, this case shows with existing data that undergraduate student organizations can create and maintain summer undergraduate interdisciplinary research programs. In fact, it was found that the support from a student organization helped fill in the voids for the summer undergraduate research program that existing programs lack, such as volunteer opportunities, conference planning, etc.

We believe we are the first research group (in the authors' knowledge) to implement two parallel research programs simultaneously as a summer undergraduate research program. This report of our preliminary findings suggests that it can be successful with the LINCR program pathway serving as an example. Specifically, it was shown that 1) undergraduates can effectively jumpstart interdisciplinary research collaborations through active participation (40 hours/week) of a research project in labs of different buildings; 2) undergraduates can effectively connect mentors from two separate labs in a biweekly capacity (.80 times/week); and 3) the LINCR program effectively promotes PIs to interact and collaborate with each other in a moderate-weak capacity with the potential for rapid growth in the future (.60 times/month and $60 \%$ moderate-weak classification of research collaboration throughout the program). 
Future study is required to better understand the effectiveness of the educational prompts as both a research instrument for evaluating the project as well as for guiding the participants. We hypothesize that these prompts have the potential to transform moderate-weak collaborations into moderate-strong and, subsequently, into strong collaborations by aligning initiates in the local community to possibly continue funding the project into the future (e.g., grant agencies like $\mathrm{NIH} / \mathrm{NSF}$ ).

Various advantages were found within the LINCR model relative to other existing undergraduate-based interdisciplinary research programs. Resources can be shared between collaborating labs, allowing for greater flexibility in projects and unforeseen advantages in mentor-mentor (e.g. learning new technique from mentor) and mentor-LF (i.e. learning new technique from fellow) interactions. In addition, because the LINCR program connects labs in parallel, the student can sustain the research by working in the partnering lab during the extended absence of one PI or the other. Educational prompts also could help the LF get a better grasp of the scope of their project and how it can be applied in real-life situations (e.g. for-profit companies, nonprofit institutions, other research labs, clinical networks, etc.). An undergraduate student organization (GTNeuro) was also found to be an effective means to act as a scaffold to support this research program because roles within the GTNeuro executive board meshed well with the requirements for the summer research program. The LINCR model also uses Google Hangout to enable remote collaboration amongst the LINCR coordinators, allowing for semiremote administration of the program (of the 4 main LINCR planning committee members, 3 were remote). The LINCR program also resulted in peripheral aftereffects in the Georgia Tech community to help advance research collaborations (e.g. CHAMP).

Problems within the LINCR model seemed to be the result of timing, that is, a lack of time to create the program's first iteration due to funding delays. This may have impacted the number of applicants for the Fellow positions as well as limiting the amount of preparation in recruiting PIs and labs for inclusion. Additionally two main problems were identified: 1) mentors were informed late about their responsibilities in relation to the LINCR program; and 2) PIs were unresponsive to feedback forms requiring many reminders to comply with feedback opportunities. These problems will be addressed in future iterations of the LINCR program.

Future improvements for the program include: 1) collecting projects earlier on in the process - defining proposals from PIs/grad students to make the projects easier to start; 2) increasing time for mentors to understand their roles and responsibilities, and possibly paying the mentors a stipend to incentivize proper mentorship; 3) follow-up interviews with mentors and PIs earlier on in the LINCR program to increase participation in the biweekly research prompt process (emails were not enough to incentivize PIs to participate in prompt process); 4) expansion of the LINCR brochure database through GTNeuro research, possibly to other schools and the local Atlanta community; and 5) integration of LINCR to other existing infrastructure in the Georgia Tech community (i.e. other student organizations, other research labs, new research centers, other initiatives). 


\section{Acknowledgements}

This work was funded by the Georgia Tech Fund for Innovation in Research and Education (GT FIRE).

We are especially grateful to the LINCR participants (Fellows, mentors, and PIs) without whom this paper would not be possible. We would also like to thank the Georgia Tech community, specifically the collaborating departments, for their support in implementing this project. 
Appendix A: LINCR Bi-weekly Structured Survey (administered to the LINCR Fellows, mentors, and PIs). These prompts were intended to identify the successes and failures of the LINCR program throughout different periods of time as well as to monitor progress and engagement in real-time.

\begin{tabular}{|c|c|c|c|}
\hline \multicolumn{4}{|c|}{ Biweekly Research Prompts Administered } \\
\hline $\begin{array}{c}\text { Biweekly } \\
\text { Research } \\
\text { Update Title }\end{array}$ & Frequency & Questions & Potential Utility \\
\hline $\begin{array}{l}\text { Research } \\
\text { Update - } \\
\text { LINCR } \\
\text { Fellows }\end{array}$ & Biweekly & $\begin{array}{l}\text { Question 1: Hours spent last } 2 \\
\text { weeks working outside of lab on a } \\
\text { project (e.g. biweekly prompts, } \\
\text { literature reviews, presentations). } \\
\text { Question 2: Hours spent in lab 1 in } \\
\text { past 2 weeks } \\
\text { Question 3: Interaction frequency } \\
\text { with lab 1 PI. } \\
\text { Question 4: Communication } \\
\text { mediums with lab 1 PI. } \\
\text { Question 5: Communication } \\
\text { frequency with lab 1 mentor. } \\
\text { Question 6: Communication } \\
\text { mediums with lab 1 mentor. } \\
\text { Question 7: What were the focuses } \\
\text { of your project in Lab 1 (please put } \\
\text { them in list format)? } \\
\text { Question 8: Have you had any } \\
\text { problems in Lab } 1 \text { these past } 2 \\
\text { weeks? If so, briefly list them. } \\
\text { Question 9: Hours spent in lab } 2 \text { in } \\
\text { past } 2 \text { weeks } \\
\text { Question 10: Interaction frequency } \\
\text { with lab 2 PI. } \\
\text { Question 11: Communication } \\
\text { mediums with lab 2 PI. } \\
\text { Question 12: Communication } \\
\text { frequency with lab 2 mentor. } \\
\text { Question 13: Communication } \\
\text { mediums with lab } 2 \text { mentor. } \\
\text { Question 14: What were the focuses } \\
\text { of your project in Lab 2 (please put } \\
\text { them in list format)? } \\
\text { Question 15: Have you had any } \\
\text { problems in Lab } 2 \text { these past } 2 \\
\text { weeks? If so, briefly list them. }\end{array}$ & 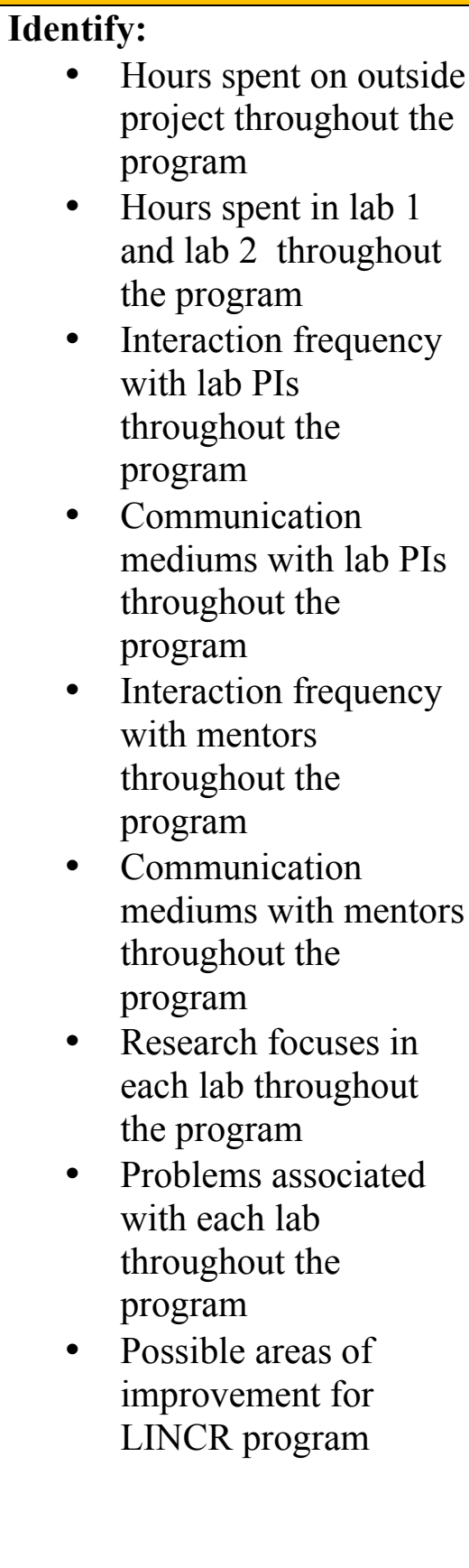 \\
\hline
\end{tabular}




\begin{tabular}{|c|c|c|c|}
\hline $\begin{array}{l}\text { Research } \\
\text { Update - } \\
\text { Mentors }\end{array}$ & Biweekly & $\begin{array}{l}\text { Question 1: Hours mentee spent in } \\
\text { lab of mentor in past } 2 \text { weeks } \\
\text { Question 2: Hours spent interacting } \\
\text { with mentee or mentee's project in } \\
\text { past } 2 \text { weeks } \\
\text { Question 3: Frequency of } \\
\text { communicating with LF's mentor } \\
\text { Question 4: Categorization of LF's } \\
\text { project with regard to mentor's own } \\
\text { project and ambitions } \\
\text { Question 5: Have you learned } \\
\text { anything useful from the LINCR } \\
\text { Fellow's project in the past } 2 \\
\text { weeks? If so, what have you } \\
\text { learned? } \\
\text { Question 6: Have you had any } \\
\text { problems with the student mentee's } \\
\text { project? If so, please briefly list } \\
\text { them in list format. } \\
\text { Question 7: Is there anything that } \\
\text { the LINCR planning committee can } \\
\text { do to help you reach your goals in } \\
\text { the program? }\end{array}$ & $\begin{array}{l}\text { Identify: } \\
\text { - The extent to which } \\
\text { mentors are } \\
\text { collaborating with } \\
\text { each other on the } \\
\text { LINCR project } \\
\text { - Useful information } \\
\text { assimilated from LF's } \\
\text { project (for mentor) } \\
\text { Problems associated } \\
\text { with the LINCR } \\
\text { program } \\
\text { Possible areas of } \\
\text { improvement for } \\
\text { LINCR program } \\
\text { Confirm: } \\
\text { - Student's hours } \\
\text { posited in research } \\
\text { update } \\
\text { Research mentor's } \\
\text { interest to support the } \\
\text { LINCR Fellow's } \\
\text { project }\end{array}$ \\
\hline $\begin{array}{l}\text { Research } \\
\text { Update - } \\
\text { Principal } \\
\text { Investigators } \\
\text { (PIs) }\end{array}$ & Monthly & $\begin{array}{l}\text { Question 1: Have you interacted wit } \\
\text { the other PI involved on this project } \\
\text { in the past month? If so, in what } \\
\text { frequency? } \\
\text { Question 2: How receptive do you } \\
\text { feel the mentor in your lab has been } \\
\text { to the LF's project this past month? } \\
\text { Question 3: How many times have } \\
\text { you communicated with the LINCR } \\
\text { fellow in the past month? } \\
\text { Question 4: In the past month, what } \\
\text { mediums have you used to } \\
\text { contact/interact with the student? } \\
\text { Question 5: In the past month, how } \\
\text { would you classify the student's } \\
\text { level of interest on their project? } \\
\text { Question 6: In the past month, what } \\
\text { mediums have you used to contact } \\
\text { the other collaborating lab PI? } \\
\text { Question 7: In the past month, how } \\
\text { would you classify the strength of } \\
\text { the collaboration with the other lab? }\end{array}$ & $\begin{array}{l}\text { Identify: } \\
\text { - } \text { PI-PI interaction } \\
\text { frequency on LINCR } \\
\text { project } \\
\text { - } \\
\text { PI-PI communication } \\
\text { mediums } \\
\text { - Subjective } \\
\text { interpretation on the } \\
\text { strength of the } \\
\text { collaboration with the } \\
\text { other lab } \\
\text { - Useful information } \\
\text { assimilated from } \\
\text { LINCR project (from } \\
\text { PI's perspective) } \\
\text { Problems associated } \\
\text { with LINCR projects } \\
\text { Possible ways to } \\
\text { improve the LINCR } \\
\text { program } \\
\text { Confirm } \\
\text { Mentor's subjective }\end{array}$ \\
\hline
\end{tabular}




\begin{tabular}{|l|l|l|}
\hline & $\begin{array}{l}\text { Question 8: Have you learned } \\
\text { anything useful from the biweekly } \\
\text { meetings or the student's project? If } \\
\text { so, briefly explain. } \\
\text { Question 9: Have you had any } \\
\text { problems with the LINCR program } \\
\text { or the LINCR Fellows's project? If } \\
\text { so, please briefly explain them. } \\
\text { Question 10: Is there anything the } \\
\text { LINCR planning committee can do } \\
\text { to help you reach your goals for the } \\
\text { program? }\end{array}$ & $\begin{array}{l}\text { interpretation on the } \\
\text { usefulness of the } \\
\text { LINCR project }\end{array}$ \\
$\begin{array}{ll}\text { Student-PI } \\
\text { communication } \\
\text { mediums }\end{array}$ & $\begin{array}{l}\text { Student's interest in } \\
\text { the LINCR project }\end{array}$ \\
& $\begin{array}{l}\text { Subjective } \\
\text { interpretation on the } \\
\text { strength of the } \\
\text { collaboration with the } \\
\text { other lab (alignment of } \\
\text { the PI perspectives) }\end{array}$ \\
\hline
\end{tabular}


Appendix B: LINCR Biweekly Educational Prompts (administered to the LINCR Fellows). These prompts were intended to serve as tutorials that would encourage the Fellow to expand the scope of the research project into the greater Atlanta community to sustain the projects into the future.

\begin{tabular}{|c|c|c|}
\hline \multicolumn{3}{|c|}{ Biweekly Prompts Administered } \\
\hline $\begin{array}{c}\text { Educational Biweekly Prompt } \\
\text { Title }\end{array}$ & Modules & Potential Application \\
\hline $\begin{array}{l}\text { Biweekly Prompt 1: Discipline } \\
\text { Identification, Historical } \\
\text { Foundations, Classes Relating to } \\
\text { Project, Existing Literature } \\
\text { Frameworks, and Self-Education } \\
\text { Media Relating to Project } \\
\text { http://gtneuro.net/?q=node/398 }\end{array}$ & $\begin{array}{l}\text { Module 1: Neurobiotechnology } \\
\text { Disciplines Relating to Project } \\
\text { Module 2: Classes at Georgia Tech } \\
\text { relating to Project } \\
\text { Module 3: Historical Foundations } \\
\text { that led to project's relevance } \\
\text { Module 4: Existing literature } \\
\text { frameworks to support project } \\
\text { Module 5: Self-learning media to } \\
\text { help understand project's scope }\end{array}$ & 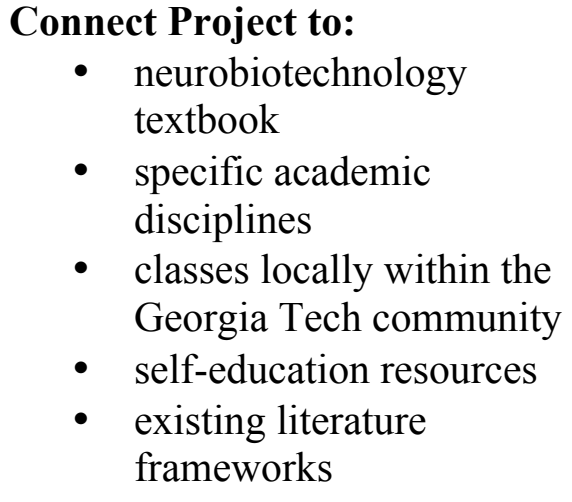 \\
\hline $\begin{array}{l}\text { Biweekly Prompt 2: Industry } \\
\text { Connections and Market } \\
\text { Analysis Relating to Project } \\
\text { http://gtneuro.net/?q=node/399 }\end{array}$ & $\begin{array}{l}\text { Module 1: Project's Relationship } \\
\text { to the Pillars of } \\
\text { Neurobiotechnology } \\
\text { Module 2: FDA Regulation } \\
\text { Relating to Project } \\
\text { Module 3: Industry Connection } \\
\text { Identification } \\
\text { Module 4: Neurobiotechnology } \\
\text { Market Analysis }\end{array}$ & $\begin{array}{l}\text { Connect Project to: } \\
\text { - } \quad \text { FDA regulations } \\
\text { - } \quad \text { Industry projects and } \\
\text { technologies/employment } \\
\text { opportunities } \\
\text { - } \\
\text { Market analysis }\end{array}$ \\
\hline $\begin{array}{l}\text { Biweekly Prompt 3: Student, } \\
\text { Nonprofit, Clinical, Professional } \\
\text { Connections Relating to Project } \\
\text { http://gtneuro.net } / \mathbf{? q}=\text { node } / \mathbf{4 0 0}\end{array}$ & $\begin{array}{l}\text { Module 1: Student Organization } \\
\text { Connections } \\
\text { Module 2: Volunteer Nonprofit } \\
\text { Connections } \\
\text { Module 3: Clinical Connections } \\
\text { Module 4: Professional } \\
\text { Organization Connections }\end{array}$ & $\begin{array}{l}\text { Connect Project to: } \\
\text { - } \quad \text { Student organizational } \\
\text { involvement at Georgia } \\
\text { Tech } \\
\text { - } \quad \text { Volunteer nonprofit } \\
\text { involvement } \\
\text { - } \quad \text { Clinical affairs } \\
\text { - } \quad \text { Professional } \\
\\
\text { organizations } \\
\end{array}$ \\
\hline $\begin{array}{l}\text { Biweekly Prompt 4: Additional } \\
\text { Emory, Georgia State, and } \\
\text { Georgia Tech Research Labs } \\
\text { Relating to Project } \\
\text { http://gtneuro.net/?q=node/401 }\end{array}$ & $\begin{array}{l}\text { Module 1: Georgia Tech Research } \\
\text { Connections } \\
\text { Module 2: Georgia State Research } \\
\text { Connections } \\
\text { Module 3: Emory Research } \\
\text { Connections }\end{array}$ & $\begin{array}{l}\text { Connect Project to: } \\
\text { - } \text { Other researchers at } \\
\text { Georgia Tech } \\
\text { - } \quad \text { Other researchers at } \\
\text { Georgia State } \\
\text { - } \quad \text { Other researchers at } \\
\text { Emory }\end{array}$ \\
\hline $\begin{array}{l}\text { Biweekly Prompt 5: Grant } \\
\text { Opportunities Relating to } \\
\text { Project, Possible Sources of }\end{array}$ & $\begin{array}{l}\text { Module 1: Internal Grant } \\
\text { Opportunities } \\
\text { Module 2: External Grant }\end{array}$ & $\begin{array}{l}\text { Connect Project to: } \\
\qquad \quad \text { Grant opportunities } \\
\text { internal to the Georgia } \\
\end{array}$ \\
\hline
\end{tabular}




\begin{tabular}{|l|l|l|}
\hline $\begin{array}{l}\text { Publication } \\
\text { http://gtneuro.net//q=node/402 }\end{array}$ & $\begin{array}{l}\text { Opportunities } \\
\text { Module 3: Presentation } \\
\text { Opportunities } \\
\text { Module 4: Publication } \\
\text { Opportunities }\end{array}$ & $\begin{array}{l}\text { Tech community } \\
\text { Grant opportunities } \\
\text { external to the Georgia } \\
\text { Tech community } \\
\text { - Opportunities to present } \\
\text { research }\end{array}$ \\
$\begin{array}{l}\text { Opportunities to publish } \\
\text { research }\end{array}$ \\
\hline $\begin{array}{l}\text { Biweekly Prompt 6: } \text { Project's } \\
\begin{array}{l}\text { Relationship to GTNeuro, Ways } \\
\text { to Expand Project Scope } \\
\text { through GTNeuro Involvement } \\
\text { http://gtneuro.net/?q=node/403 }\end{array}\end{array}$ & $\begin{array}{l}\text { Module 1: Identification of Parts } \\
\text { of GTNeuro relevant to Project } \\
\text { Module 2: Ways to get Involved in } \\
\text { GTNeuro to expand Project's } \\
\text { Scope }\end{array}$ & $\begin{array}{l}\text { Connect Project to: } \\
\text { The Neuroscience Club at } \\
\text { Georgia Tech (GTNeuro) }\end{array}$ \\
\hline
\end{tabular}




\section{References}

1. Fasse BB, Benkeser P. Developing the Global Biomedical Engineer Through a 12-Month International Undergraduate Research Experience in the U.S. and China. American Society for Engineering Education. 2011.

2. Board NS. Arlington VA: Science and Engineering Indicators 2012; 2012. Available from: http://www.nsf.gov/statistics/seind12/c4/c4s1.htm\#s1.

3. Desai KV, Gatson SN, Stiles TW, Stewart RH, Laine GA, Quick CM. Integrating research and education at research-extensive universities with research-intensive communities. Advances in physiology education. 2008;32(2):136-41.

4. Haen KM, Raman DR, Polush E, Kemis M. Training the Next Generation of Creative, Innovative and Adaptive Scientists and Engineers: The NSF Engineering Research Center for Biorenewable Chemicals (CBiRC) Research Experience for Undergraduates. Education for Chemical Engineers. 2012.

5. Perez-Castillejos R, Hunter WC, Mantilla B, Ivanov D, editors. BioMEMS Summer Bioengineering Institute: Integrating engineering and biology education through BioMEMS design, fabrication, and test. Integrated STEM Education Conference (ISEC), 2012 IEEE 2nd; 2012: IEEE.

6. Wilson DS, Fang B, Dalton WS, Meade CD, Koomen JM. An ET-CURE Pilot Project Supporting Undergraduate Training in Cancer Research, Emerging Technology, and Health Disparities. Journal of Cancer Education. 2012:1-10.

7. Rhoten D. A multi-method analysis of the social and technical conditions for interdisciplinary collaboration. Final Report, National Science Foundation BCS-0129573. 2003.

8. Stone JE, Benfey PN, You L. Promoting Collaborative Interdisciplinary Research at the Duke Center for Systems Biology. ACS Synthetic Biology. 2012;1(5):153-5.

9. Ryser L, Halseth G, Thien D. Strategies and intervening factors influencing student social interaction and experiential learning in an interdisciplinary research team. Research in Higher Education. 2009;50(3):248-67.

10. Takoudis C, Neudeck G, Kvam E, editors. Interdisciplinary undergraduate research in microelectronic materials and processing. University/Government/Industry Microelectronics Symposium, 1995, Proceedings of the Eleventh Biennial; 1995: IEEE.

11. Meah YS, Smith EL, Thomas DC. Student - Run Health Clinic: Novel Arena to Educate Medical Students on Systems - Based Practice. Mount Sinai Journal of Medicine: A Journal of Translational and Personalized Medicine. 2009;76(4):344-56.

12. Clase KL, Hein PW, Pelaez NJ. Demand for interdisciplinary laboratories for physiology research by undergraduate students in biosciences and biomedical engineering. Advances in Physiology Education. 2008;32(4):256-60.

13. Fasse BB. " No Guarantees": An Ethnography of Transition to Parenthood in Normative Lifespan Development: Georgia State University; 1993.

14. Yin RK. Case study research: Design and methods: Sage Publications, Incorporated; 2008.

15. Merriam SB. Case study research in education: A qualitative approach: Jossey-Bass; 1988.

16. Stake RE. Multiple case study analysis: Guilford Press New York; 2006.

17. Geertz C. Thick description: Toward an interpretive theory of culture. Culture: critical concepts in sociology. 1973;1:173-96.

18. Goetz JP, LeCompte MD. Ethnography and qualitative design in educational research: Academic Press Orlando, FL; 1984.

19. Guba EG, Lincoln YS. Naturalistic inquiry: Sage Publications, Incorporated; 1985.

20. Measor L. Interviewing: A strategy in qualitative research. Strategies of educational research:

Qualitative methods. 1985:55-77. 
21. Spradley JP, Baker K. Participant observation: Holt, Rinehart and Winston New York; 1980.

22. Glaser BG, Strauss AL. The discovery of grounded theory: Strategies for qualitative research: Aldine de Gruyter; 1967.

23. Schacter DL. The seven sins of memory: Insights from psychology and cognitive neuroscience. American psychologist. 1999;54(3):182. 